\title{
Effects of a wheat bran extract containing arabinoxylan oligosaccharides on gastrointestinal health parameters in healthy adult human volunteers: a double-blind, randomised, placebo-controlled, cross-over trial
}

\author{
Isabelle E. J. A. François ${ }^{1}$, Olivier Lescroart ${ }^{1}$, Wim S. Veraverbeke ${ }^{1}$, Massimo Marzorati ${ }^{2}$, \\ Sam Possemiers ${ }^{2}$, Pieter Evenepoel ${ }^{3}$, Henrike Hamer ${ }^{4}$, Els Houben ${ }^{4}$, Karen Windey ${ }^{4}$, Gjalt W. Welling ${ }^{5}$, \\ Jan A. Delcour ${ }^{6}$, Christophe M. Courtin ${ }^{6}$, Kristin Verbeke ${ }^{4}$ and Willem F. Broekaert ${ }^{1}$ \\ ${ }^{1}$ FUGEIA NV, Arenberg Science Park, Gaston Geenslaan 1, B-3001 Leuven, Belgium \\ ${ }^{2}$ Laboratory of Microbial Ecology and Technology (LabMet), Ghent University, Coupure Links 653, B-9000 Gent, Belgium \\ ${ }^{3}$ Division of Nephrology, University Hospitals UZ Leuven, Herestraat 49, B-3000 Leuven, Belgium \\ ${ }^{4}$ Translational Research for Gastrointestinal Disorders (Targid) and Leuven Food Science and Nutrition Centre (LFoRCe), \\ University Hospitals UZ Leuven, Herestraat 49, OEN1, Box 701, B-3000 Leuven, Belgium \\ ${ }^{5}$ Department of Medical Microbiology, University Medical Center Groningen, University of Groningen, Hanzeplein 1, 9713 \\ GZ Groningen, The Netherlands \\ ${ }^{6}$ Laboratory of Food Chemistry and Biochemistry and Leuven Food Science and Nutrition Research Centre (LFoRCe), \\ Katholieke Universiteit Leuven, Kasteelpark Arenberg 20, B-3001 Leuven, Belgium
}

(Submitted 28 September 2011 - Final revision received 16 January 2012 - Accepted 19 January 2012 - First published online 28 February 2012)

\section{Abstract}

Wheat bran extract (WBE) is a food-grade soluble fibre preparation that is highly enriched in arabinoxylan oligosaccharides. In this placebo-controlled cross-over human intervention trial, tolerance and effects on colonic protein and carbohydrate fermentation were studied. After a 1-week run-in period, sixty-three healthy adult volunteers consumed 3,10 and $0 \mathrm{~g}$ WBE/d for 3 weeks in a random order, with 2 weeks' washout between each treatment period. Fasting blood samples were collected at the end of the run-in period and at the end of each treatment period for analysis of haematological and clinical chemistry parameters. Additionally, subjects collected a stool sample for analysis of microbiota, SCFA and $\mathrm{pH}$. A urine sample, collected over $48 \mathrm{~h}$, was used for analysis of $p$-cresol and phenol content. Finally, the subjects completed questionnaires scoring occurrence frequency and distress severity of eighteen gastrointestinal symptoms. Urinary $p$-cresol excretion was significantly decreased after WBE consumption at $10 \mathrm{~g} / \mathrm{d}$. Faecal bifidobacteria levels were significantly increased after daily intake of $10 \mathrm{~g}$ WBE. Additionally, WBE intake at $10 \mathrm{~g} / \mathrm{d}$ increased faecal SCFA concentrations and lowered faecal $\mathrm{pH}$, indicating increased colonic fermentation of WBE into desired metabolites. At $10 \mathrm{~g} / \mathrm{d}$, WBE caused a mild increase in flatulence occurrence frequency and distress severity and a tendency for a mild decrease in constipation occurrence frequency. In conclusion, WBE is well tolerated at doses up to $10 \mathrm{~g} / \mathrm{d}$ in healthy adults volunteers. Intake of $10 \mathrm{~g}$ WBE$/ \mathrm{d}$ exerts beneficial effects on gut health parameters.

Key words: Wheat bran extract: Prebiotics: Protein fermentation reduction: Colonic SCFA: p-Cresol

Wheat bran extract (WBE) is a food-grade preparation that is highly enriched in arabinoxylan oligosaccharides (AXOS) and that is produced by enzymic extraction from wheat bran. The AXOS in WBE consist of a backbone of $\beta$-1,4-linked D-xylopyranosyl residues (xylose), some of which are monoor di-substituted at the $\mathrm{C}(O) 2$ and/or $\mathrm{C}(O) 3$ position with $\alpha$-L-arabinofuranosyl residues (arabinose) ${ }^{(1-4)}$. Some of the xylose units in the backbone of AXOS carry glucuronic acid at the $\mathrm{C}(O) 2$ position, whereas some of the arabinose units are ester-linked at the
$\mathrm{C}(O) 5$ position with ferulic acid ${ }^{(1-4)}$. The AXOS in WBE form a heterogeneous mixture of oligosaccharides differing in degree of polymerisation and degree of substitution of the xylan backbone. Besides AXOS, WBE also contains up to $15 \%$ glucans (mainly $\beta$-D-(1,3)(1,4)-linked glucan oligomers) and low levels of proteins, minerals and monosaccharides ${ }^{(5)}$.

AXOS are non-digestible fermentable prebiotic oligosaccharides that selectively stimulate the growth of bifidobacteria in vitro ${ }^{(6)}$, in caeca of chickens ${ }^{(7,8)}$, in caeca of rats ${ }^{(9)}$ and in

Abbreviations: AE, adverse event; AXOS, arabinoxylan oligosaccharides; EE, efficacy evaluable; FISH, fluorescent in situ hybridisation; PP, per protocol; WBE, wheat bran extract.

*Corresponding author: Dr Isabelle E. J. A. François, fax +32 16751 378, email isabelle.francois@fugeia.com 
the colon of healthy human volunteers ${ }^{(10)}$. The evidence for AXOS having prebiotic activity has been recently reviewed ${ }^{(11)}$. Moreover, AXOS consumption decreases the excretion of urinary and faecal $p$-cresol, a marker of intestinal protein fermentation $^{(10,12)}$. Colonic protein fermentation is often regarded as detrimental to host health, in particular with respect to colon toxicity, mutagenicity and carcinogenicity ${ }^{(13)}$. Fermentation of proteins by the microbiota produces a series of potentially toxic substances including ammonia, amines, sulfur-containing compounds and phenolic compounds such as $p$ cresol $^{(14-18)} \cdot p$-Cresol, a tyrosine metabolite produced in the colon by bacterial fermentation, is relevant to health status since it is considered the prototype of protein-bound uraemic toxins in chronic kidney disease ${ }^{(19)}$.

In addition to causing a decrease in protein fermentation, fermentation of AXOS enhances the production of SCFA in vitro and in rats ${ }^{(9,20,21)}$. SCFA are produced upon saccharolytic fermentation of carbohydrates and are considered to be beneficial to the host ${ }^{(22)}$.

Several studies have indicated that SCFA improve the intestinal barrier function and reduce inflammation mainly by inhibition of NFKB activation ${ }^{(23)}$. SCFA stimulate epithelial cell proliferation and differentiation in the large bowel in vivo ${ }^{(24)}$, and SCFA, butyrate in particular, are the major energy source for the colonocytes ${ }^{(25)}$. In addition, in vitro and animal studies have shown an anti-carcinogenic potential of increased SCFA production ${ }^{(26)}$. Butyrate, in particular, has received much attention as a potential chemopreventive agent by inhibiting promotion of neoplastic cells to cancer or by removing degraded cells from the tissue ${ }^{(27)}$. However, SCFA are probably not solely responsible for the anticarcinogenic potential of wheat dietary fibre as was suggested by Borowicki et $a l .{ }^{(28)}$. SCFA may provide further benefits beyond their contribution to gut health. For example, acetate and propionate can modify hepatic lipid metabolism. Propionate serves as a substrate for gluconeogenesis and may inhibit cholesterol synthesis, whereas acetate is utilised as a substrate for the synthesis of longer-chain fatty acids ${ }^{(26)}$. A possible role for increased SCFA production on glucose homeostasis is supported by the finding that patients lacking a colon after surgical resection exhibit a reduction in insulin sensitivity ${ }^{(29)}$. These effects may be due to the fact that SCFA are ligands for G-protein-coupled receptors expressed on adipocytes, enteroendocrine L-cells and immune cells ${ }^{(30)}$. Other studies have reported that SCFA either directly or indirectly activate AMP-activated protein kinase (AMPK) in the liver ${ }^{(31)}$. AMPK is a key enzyme in the regulation of energy metabolism, and its activation increases skeletal muscle glucose uptake ${ }^{(32)}$ and inhibits hepatic glucose production ${ }^{(33)}$.

Intake of fermentable non-digestible carbohydrates has in some cases been noted to cause undesired gastrointestinal effects, including flatulence, abdominal discomfort and diarrhoea ${ }^{(34)}$. Additionally, the consumption of fermentable non-digestible carbohydrates, such as inulin and galactooligosaccharides, has been associated in some studies, but not all, with a number of other gastrointestinal discomfort effects including acid reflux and heartburn, belching/burping, borborygmi, colic (spasmodic abdominal pain), laxation and nausea ${ }^{(35)}$. Such responses, though transient, affect the perception of well-being by consumers and, hence, their acceptance of food products containing these fermentable carbohydrates.

The purpose of the present study was to evaluate the effect of WBE on gastrointestinal health parameters in healthy adult volunteers. In the present study, WBE was administered at different dosages and in a larger study population as compared with previous studies ${ }^{(10,36)}$. Additionally, the effect of WBE administration on colonic carbohydrate fermentation was investigated through measurement of faecal levels of SCFA while previously breath $\mathrm{H}_{2}$ was used to analyse carbohydrate fermentation, and the effect on colonic protein fermentation was analysed through measurement of urinary and serum levels of phenolic compounds. Tolerance to WBE was assessed through self-reported scoring by the subjects on gastrointestinal symptoms. Safety was evaluated by assessing the occurrence of adverse events (AE) and by analysing the effect on haematological and clinical blood chemistry parameters.

\section{Experimental methods}

\section{Composition of wheat bran extract}

WBE (Brana Vita ${ }^{\circledR}$ 200) was produced from wheat bran by Fugeia NV, using a procedure based on that described by Swennen et $a l .^{(1)}$. WBE was analysed for the content of AXOS, the AXOS average degree of polymerisation, its arabinose:xylose ratio, bound ferulic acid and glucuronic acid, glucose as part of poly/oligosaccharides, mannose as part of poly/oligosaccharides, galactose as part of poly/oligosaccharides, free monosaccharides, moisture, protein and ash by analytical procedures outlined previously ${ }^{(5)}$. Lipid content was measured by a Soxhlet method using petroleum ether extraction according to method ISO 1443 (International Organization for Standardization). The presence of mesophilic bacteria, yeasts, fungi and Salmonella was determined according to methods ISO 4833, ISO 7954, ISO 7954 and ISO 6579/ cor1, respectively. The presence of the heavy metals As, Cd, $\mathrm{Pb}$ and $\mathrm{Hg}$ was determined according to a Eurofins method based on ISO $17294-1 / 2$.

Table 1 shows the composition of the WBE preparation used in the present study. It consisted of $79.0 \%$ AXOS (on a DM basis), had an average degree of polymerisation of 5 and an arabinose:xylose ratio of $0 \cdot 19$.

\section{Subjects}

Based on the dataset of an earlier human intervention trial with $\mathrm{WBE}^{(10)}$, an evaluable sample size of forty was expected to provide $80 \%$ power (two-sided, $\alpha=0.05$ ) for detecting a statistically significant difference in faecal bifidobacteria levels (the primary outcome variable of the present study) between WBE treatment and placebo treatment. Based on this power analysis, it was decided to recruit approximately sixty volunteers for the present trial. A total of sixty-three healthy subjects (thirty women and thirty-three men, mean 
Table 1. Characterisation of the wheat bran extract preparation

\begin{tabular}{|c|c|}
\hline & Composition \\
\hline AXOS (\% DM) & $79 \cdot 0$ \\
\hline Of which xylo-oligosaccharides $\left(X \mathrm{OS}_{\mathrm{DP} 2-9}\right)(\% \mathrm{DM})$ & 39.5 \\
\hline Of which xylobiose $\left(\mathrm{XOS}_{\mathrm{DP} 2}\right)(\% \mathrm{DM})$ & $22 \cdot 2$ \\
\hline Average DP of AXOS & 5 \\
\hline$A: X$ ratio of $A X O S$ & 0.19 \\
\hline Glucuronic acid bound to AXOS (\% DM) & 1.0 \\
\hline Ferulic acid bound to AXOS (\% DM) & 1.5 \\
\hline Glucose as part of poly/oligosaccharides (\% DM) & $12 \cdot 2$ \\
\hline Galactose as part of poly/oligosaccharides (\% DM) & 1.5 \\
\hline Total free monosaccharides (\% DM) & 0.5 \\
\hline Protein $(\mathrm{N} \times 6.25)(\% \mathrm{DM})$ & 0.6 \\
\hline Total lipids (\% DM) & $<0.5$ \\
\hline Ash (\% DM) & 0.2 \\
\hline DM (\%) & $96 \cdot 4$ \\
\hline
\end{tabular}

AXOS, arabinoxylan oligosaccharides; XOS, xylo-oligosaccharides; DP, degree of polymerisation; $A: X$ ratio, arabinose:xylose ratio.

age 42 (SD 17) years, mean BMI 23.3 (sD 3.2) kg/m², all of Caucasian ethnicity) participated in the study. The population encompassed healthy adult subjects of different age groups: twenty-five individuals were aged between 18 and 30 years, five were aged 31-40 years, eight were aged $41-50$ years, fourteen were aged 51-60 years and eleven were aged 6185 years. Exclusion criteria were using a low-energy diet or other extreme dietary habits in the 6 weeks before the start of the clinical trial, intake of antibiotics in the 3 months before the start of the clinical trial, intake of medication or dietary supplements influencing gastrointestinal tract processes in the 2 weeks before the start of the clinical trial, abdominal surgery in the past (with the exception of appendectomy), serious illness (defined as more than 2 weeks unable to work) in the 3 months before the start of the clinical trial, complete anaesthetics in the month before the start of the clinical trial, history of chronic gastrointestinal conditions such as inflammatory bowel disease and irritable bowel syndrome, allergy to wheat products, coeliac disease, alcohol abuse, or smoking of more than five cigarettes per $\mathrm{d}$. Female volunteers were excluded if pregnant or lactating. During the study, the subjects ate their usual diet, but were asked to have a regular eating pattern (three meals per $\mathrm{d}$ ). The intake of food substances containing probiotics and/or prebiotics was forbidden. At the time of inclusion, all subjects were informed about proand prebiotics and the food products containing them. The subjects were asked to read food labels carefully to check the content for the addition of pro- and/or prebiotics. The present study was conducted according to the guidelines laid down in the Declaration of Helsinki and all procedures involving human subjects were approved by the Ethics Committee of the University Hospital UZ Leuven, Belgium (approval no. ML5282). Written informed consent was obtained from all subjects. Compliance was assessed by inquiry and by counting the returned bottles at the end of each intervention. Non-compliance was defined as not taking $100 \%$ of the required drinks during at least 16 of the $21 \mathrm{~d}$ treatment period and/or not taking $100 \%$ of the required drinks during at least 2 of the 3 last days before stool collection.

\section{Study design}

Figure 1 presents a schematic overview of the randomised, placebo-controlled, double-blind, cross-over study. The study started with a 1-week run-in period, followed by three 3 -week treatment periods with 2-week washout periods in between two consecutive treatment periods. Each subject underwent three treatment periods. During the treatment periods, the following treatments were applied, yet not necessarily in this order: placebo treatment; treatment with WBE at $3 \mathrm{~g} / \mathrm{d}$ (low WBE dose, which equals $2.4 \mathrm{~g}$ AXOS/d); and treatment with $10 \mathrm{~g}$ WBE/d (high WBE dose, which equals $8 \mathrm{~g}$ AXOS/d). Clinic visits took place at the end of the run-in period and at the end of each treatment period. WBE and placebo were administered as non-carbonated soft drinks, of which the volunteer had to drink twice daily $70 \mathrm{ml}$, once after breakfast and once after dinner. Consumption

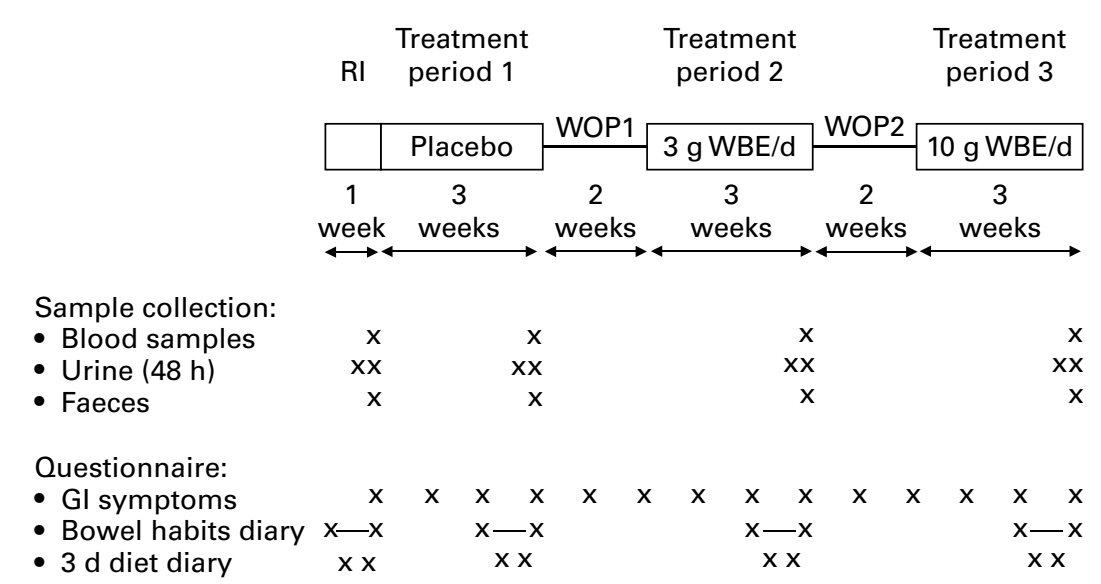

Fig. 1. Schematic representation of the study design. The study started with a 1-week run-in (RI) period, followed by three 3 -week treatment periods in which wheat bran extract (WBE) was taken in by the subjects at a dose of $0 \mathrm{~g} / \mathrm{d}$ (placebo), $3 \mathrm{~g} / \mathrm{d}$ and $10 \mathrm{~g} / \mathrm{d}$ (not necessarily in this order). Blood, urine and faecal samples were taken at different, indicated, time points. The subjects completed weekly a questionnaire assessing the occurrence frequency and distress severity of eighteen gastrointestinal symptoms. Additionally, subjects recorded in the bowel habits diary the number of bowel movements and stool consistency during the 1 -week RI period and during the last week of each 3-week treatment period. WOP, washout period; GI, gastrointestinal. 
of the soft drinks took place at the volunteers' home. The WBE-containing soft drinks contained sucrose, colorant, flavour, citric acid and potassium sorbate. The placebo soft drink had the same composition as the WBE-containing soft drink, except that WBE was omitted and that $0.25 \mathrm{~g}$ tricalcium phosphate per litre was added to mimic the turbidity of the WBE-containing soft drinks. Subjects were randomly assigned to one of six randomisation groups, each randomisation group differing in the treatment sequence by which the three types of drinks were to be consumed. A list of unique three-digit numbers (volunteer numbers) was generated in a random way. Each volunteer number was linked with the number of a randomisation group. At the screening visit, an eligible subject who gave informed consent was randomly assigned to a volunteer number. Subjects started the study at any of three different inclusion periods, with the starting date of the first inclusion period and the starting date of the third inclusion period being $21 \mathrm{~d}$ apart. The study was a doubleblind study. The investigators that had direct contact with the subjects were blinded to the treatment since they were unaware of the randomisation groups to which the subjects were assigned. Moreover, the appearance and the taste of the different soft drinks were near identical.

\section{Sample collection}

Blood samples. At the end of the run-in period and at the end of each 3-week treatment period, fasting serum and plasma samples were collected from those thirty-nine volunteers who had voluntarily provided consent for drawing blood during the study. EDTA, lithium heparin and fluoride/ oxalate were used as anti-coagulants. Immediately after blood collection, plasma and serum were transferred to the central laboratory facility of the University Hospitals UZ Leuven for standard analysis of haematology and clinical chemistry parameters. Samples of EDTA-plasma were stored at $-20^{\circ} \mathrm{C}$ for the analysis of lipid peroxides. Samples of serum were stored at $-80^{\circ} \mathrm{C}$ for the analysis of $p$-cresylsulfate.

Urine samples. From the morning of day 5 until the morning of day 7 of the run-in period and from the morning of day 19 until the morning of day 21 of each 3-week treatment period, urine was collected in receptacles containing $1.0 \mathrm{~g}$ neomycin. The volume of all urine fractions was measured and the samples were stored at $-20^{\circ} \mathrm{C}$ until the analysis of $p$-cresol and phenol. The completeness of each urine collection was estimated from the calculation of the observed:expected creatinine ratio, as proposed by Knuiman et $a l .{ }^{(37)}$. The ratio of the observed:expected creatinine excretion was calculated using the formula ( $(24 \mathrm{~h}$ creatinine $(\mathrm{mmol}) \times 113 \mathrm{~g} / \mathrm{mol}) /(24 \mathrm{mg} / \mathrm{kg} \times$ body weight $(\mathrm{kg})))$ for males and $((24 \mathrm{~h}$ creatinine $(\mathrm{mmol}) \times 113 \mathrm{~g} / \mathrm{mol}) /(21 \mathrm{mg} /$ $\mathrm{kg} \times$ body weight $(\mathrm{kg})))$ for females ${ }^{(37)}$. When the ratio was lower than $0 \cdot 7$, the urine collection was considered as incomplete ${ }^{(37,38)}$, and the corresponding data were omitted for analysis.

Faecal samples. On the evening of day 5 or during day 6 of the run-in period as well as from the evening of day 19 or during day 20 of each 3-week treatment period, one bowel movement was collected and immediately frozen by the subjects. The faecal sample was kept frozen until delivery at the clinic. After $6 \mathrm{~d}$ storage at $-20^{\circ} \mathrm{C}$ at the clinic, the faecal samples were thawed. Subsequently, $2.5 \mathrm{~g}$ were immediately fixed in paraformaldehyde using the procedure described by Franks et $a l .{ }^{(39)}$ for microbial analysis by fluorescent in situ hybridisation (FISH). Samples of the faecal samples were stored at $-20^{\circ} \mathrm{C}$ until the analysis of SCFA, $\mathrm{pH}$ and ammonia.

\section{Recording of adverse events}

Subjects were asked to record whether they had suffered from a medical condition (differing from the baseline recordings), had to take new medication or had to stop taking previously reported medication. Additionally, at each clinic visit, the subjects were asked these questions. This information was recorded in the appropriate section of the case report form.

\section{Biochemical analyses of blood samples}

Haematological parameters, clinical blood chemistry parameters (including liver enzymes and parameters of kidney function), blood lipids, blood vitamins and blood minerals were analysed using standard laboratory techniques for blood analysis. Serum $p$-cresylsulfate content was determined as described by Meijers et $a l^{(18)}$.

\section{Microbiological analyses of faecal samples}

Faecal samples were analysed for composition of the faecal microbiota. FISH was used to count the number of different bacterial groups in paraformaldehyde-fixed faecal samples. Processing of fixed samples and FISH analysis were performed as described by Franks et $a l .{ }^{(39)}$. For total bacterial cell counts, 4'-6-diamidino-2-phenylindole (DAPI) was used. The probes used for group-specific FISH analysis were Bif164 for the genus Bifidobacterium ${ }^{(40)}$, Lab158 for the Lactobacillus-Enterococcus group ${ }^{(41)}$, an equimolar mixture of Chis150 and Clit135 for the Clostridium histolyticumlituseburense group $^{(39)}$, Fprau645 for the Faecalibacterium prausnitzii group ${ }^{(42)}$ and Rint623 for the Roseburia-Eubacterium rectale group ${ }^{(43)}$. Fluorescent cells were counted as described earlier ${ }^{(44)}$. Percentage of bifidobacteria was calculated as the ratio of the absolute amounts of bifidobacteria to the total bacterial cell count.

\section{Biochemical analyses of faecal samples}

Concentrations of the SCFA acetate, propionate and butyrate were determined as described by Van de Wiele et $a l^{(45)}$, using 2-methylhexanoic acid as an internal standard. Total SCFA was defined as the sum of acetate, propionate and butyrate.

To determine the faecal $\mathrm{pH}$, a sample of approximately $1 \mathrm{~g}$ faeces was homogenised by mixing into $10 \%(\mathrm{w} / \mathrm{w})$ demineralised water ${ }^{(46)}$. The $\mathrm{pH}$ was immediately measured upon homogenisation. Ammonia levels were measured on the 
same faecal slurries as used for $\mathrm{pH}$ determination, following the procedure described by Bremner \& Keeney ${ }^{(47)}$.

\section{Biochemical analyses of urine samples}

Total $p$-cresol and phenol contents in urinary samples were

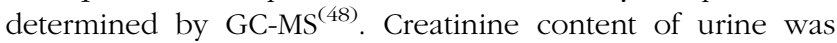
measured using a standard laboratory urinology protocol. $p$ Cresol and phenol levels were corrected for creatinine content ( $\mathrm{mg} p$-cresol/g creatinine; $\mathrm{mg}$ phenol/g creatinine).

\section{Recording of gastrointestinal symptoms}

A questionnaire assessing gastrointestinal symptoms was established following the guidelines of the US Food and Drug Administration for the development of patient-reported outcomes. The following eighteen gastrointestinal symptoms were scored: diarrhoea, constipation, painful bowel movement, blood in stool, abdominal pain, bloating, abdominal cramps, abdominal stretching, borborygmy, flatulence, burping, acid regurgitation, retrosternal burning, nausea, vomiting, indigestion, difficulty with swallowing and hoarseness/sore throat. Occurrence frequency of the symptoms was graded on a five-step scale ranging from never (0), occasionally (1), frequently (2), nearly always (3) to always (4). Distress severity of the symptoms was graded on a five-step scale ranging from no (0), minimal (1), mild (2), moderate (3) to severe (4) distress, as described by van Munster et $a l .{ }^{(49)}$. Subjects were asked to grade these gastrointestinal symptoms weekly during the trial.

\section{Recording of stool parameters}

During the run-in period and during the last week of every 3-week treatment period, defecation frequency as well as stool consistency (according to the Bristol Stool Form Scale ${ }^{(50)}$ ) were recorded daily using appropriate questionnaires. Average defecation frequency was calculated as the number of stools divided by the numbers of days of diary recording. Average stool consistency was calculated as the sum of Bristol Stool Form Scales divided by the number of stools. The composite parameter of defecation frequency and stool consistency (also called the Bristol Composite Measure) was calculated as the sum of Bristol Stool Form Scales divided by the number of days of diary recording ${ }^{(51)}$.

\section{Dietary composition}

Subjects were asked to record all food and beverage intake of days 3-5 of the run-in period and of days 17-19 of each 3 -week treatment period. These data were used to calculate the average daily energy intake $(\mathrm{kJ})$, the average percentage of energy from carbohydrates, the average percentage of energy from lipids and the average percentage of energy from proteins. These calculations were made using the Nubel Food Planner (www.nubel.be). During treatment with $10 \mathrm{~g} \mathrm{WBE} / \mathrm{d}$, an additional $218 \mathrm{~kJ} / \mathrm{d}(52 \mathrm{kcal} / \mathrm{d})$ and $9.5 \mathrm{~g}$ carbohydrates/d were added to the reported data; during treatment with $3 \mathrm{~g} \mathrm{WBE} / \mathrm{d}$ an additional $147.3 \mathrm{~kJ} / \mathrm{d}(35.2$ $\mathrm{kcal} / \mathrm{d}$ ) and an additional $7 \cdot 8 \mathrm{~g}$ carbohydrates/d were added to the reported data; during the placebo treatment period an additional $117 \mathrm{~kJ} / \mathrm{d}(28 \mathrm{kcal} / \mathrm{d})$ and $7 \mathrm{~g}$ carbohydrates/d were added to the reported data.

\section{Statistical analysis of efficacy variables}

All tests of significance were performed at $\alpha=0.05$ and twosided, unless otherwise stated. Assumptions of normality of residuals were investigated for each variable using the Shapiro-Wilk test ${ }^{(52)}$. When the data were normally distributed, linear mixed models were applied to the raw data as such, except for the microbiota data which were log-transformed before analysis, as is customary for microbiota counts. When the distribution was not approximated by a normal curve, values were ranked before analysis and the linear mixed model was performed on the rank-transformed data ${ }^{(53)}$. Ties occurring during the rank-transformation were replaced by their average rank. The data to estimate the fixed-effect parameter for the run-in of the response remained unranked.

Evaluations of the effects of treatment on the efficacy variables were completed on an efficacy evaluable (EE) population, defined as all randomised subjects who received placebo and at least one serving of at least one WBE-containing soft drink and who provided at least one post-randomisation outcome data point during each of the two treatment phases. Subjects who took antibiotics during or before the placebo treatment period or subjects who took antibiotics during or before an AXOS treatment period that was not the last treatment period were excluded from the EE population. Additionally, evaluations of the treatment effects on the efficacy variables were also completed on a per protocol (PP) population, a subset of $\mathrm{EE}$ subjects who completed the study, were compliant as defined above, who did not take antibiotics or other forbidden medications or products and had no major protocol violations.

Treatment effects as well as treatment $\times$ treatment sequence and treatment $x$ inclusion period interaction effects were tested with linear mixed models using conditional $F$ and $t$ tests $^{(54)}$ (significance at $\alpha=0 \cdot 1$ ). The single-step Tukey post hoc multiple-comparison procedure was used for the pairwise comparisons of the treatments, using R's multcomp package $^{(55)}$. When no significant interactions were found, treatment differences were evaluated based on the main effect model. In the case of significant interactions, treatment differences were evaluated within each treatment sequence group or within each inclusion period group. Next to that, the overall differences were also analysed by aggregating over the interaction effects in the model. Aggregation over the interaction effects was done by setting up a linear combination of the treatment differences for each treatment sequence group and/or inclusion period group, giving equal weights to either treatment sequence group and/or inclusion period group. Efficacy results are presented for the PP population since no differences between the $\mathrm{EE}$ and $\mathrm{PP}$ results were observed. 


\section{Statistical analysis of safety parameters}

The safety population was defined as all randomised subjects who received at least one serving of WBE. Safety was analysed using the emergent $\mathrm{AE}$ and the changes in clinical blood parameters in the safety population. An AE was attributed to the treatment period during which the AE started. An AE that started during a washout period was attributed to the treatment preceding the specific washout period. In a first analysis of the changes in clinical blood parameters, the occurrence of adverse shifts in clinical blood parameters was determined. For a given subject, a shift in a blood parameter was considered to be adverse when the blood parameter value after treatment was either (i) outside the normal range while the corresponding baseline value of that subject was within the normal range, (ii) below the normal range while the corresponding baseline value was above the normal range or (iii) above the normal range while the corresponding baseline value was below the normal range. McNemar's test was used to compare differences in $\mathrm{AE}$ frequencies and differences in blood parameter adverse shifts among the three treatments $(\alpha=0.017$, Sidak correction for three comparisons) ${ }^{(56)}$. A second analysis of the clinical blood parameters was performed as defined for the efficacy analysis, but applied to the safety population.

\section{Results}

\section{Participant characteristics}

The disposition of all study participants is presented in Fig. 2. A total of eighty-eight volunteers were screened and sixty-six were randomised to any of the six different randomisation groups. Of these, three volunteers terminated the study prematurely during the run-in period: two volunteers decided to terminate the study for personal non-medical reasons; the third volunteer was asked to terminate the study because of antibiotic intake during the run-in period. Since these volunteers did not receive any WBE serving, they were excluded from the safety population. Hence, sixty-three volunteers were included in the safety population. Of these, fifty-eight were included in the EE population and fifty-seven in the PP population.

Baseline demographics and anthropometric characteristics for the PP population are presented for the six randomisation groups in Table 2. No significant differences could be observed at baseline between the six randomisation groups with respect to sex, age, BMI, faecal bifidobacteria level, defecation frequency, cholesterol content, LDL-cholesterol and TAG content. A significant difference at baseline was observed for HDL-cholesterol content, indicating that randomisation with respect to HDL-cholesterol was suboptimal.

\section{Analysis of safety variables}

Analysis of emergent adverse events. AE were categorised in eleven categories according to the National Cancer Institute Common Terminology Criteria for Adverse Events v3.0 before the unblinding of the study. Statistical analysis of the $\mathrm{AE}$ in the safety population revealed no difference between the three treatments in frequency of any of the different $\mathrm{AE}$ categories $(P>0 \cdot 1)$.

Analysis of haematological and clinical chemistry parameters. In a first analysis, the occurrence of adverse shifts in clinical blood parameters was determined in the safety population. Statistical analysis indicated no significant differences in occurrence frequency of adverse shifts between the three treatments $(P>0 \cdot 1)$.

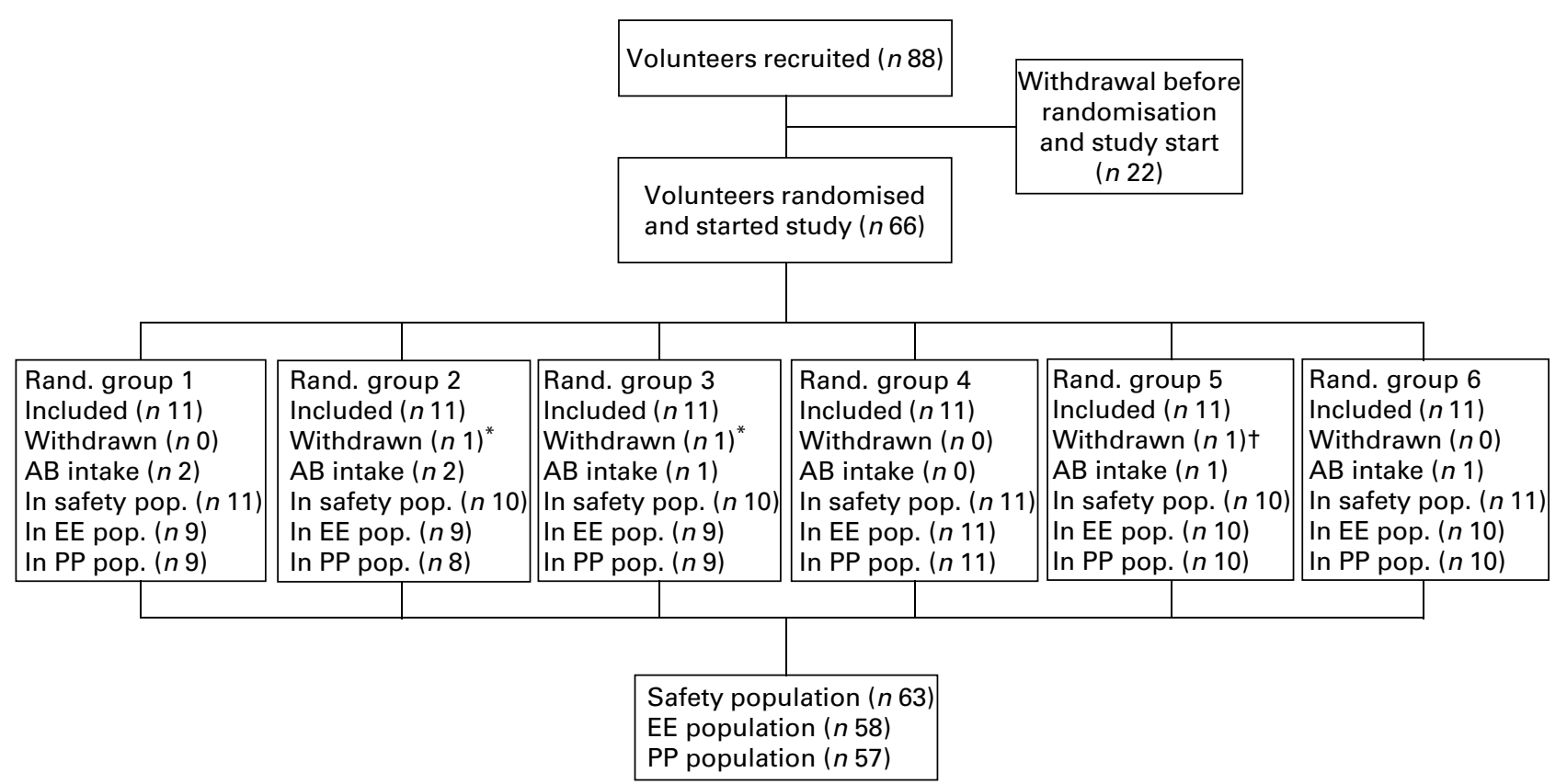

Fig. 2. Volunteer disposition. Rand., randomisation; AB, antibiotics; safety pop., safety population; EE pop., efficacy evaluable population; PP pop., per protocol population. * Reason for withdrawal: personal, non-medical. † Reason for withdrawal: intake of $A B$ during run-in period. 


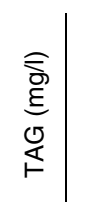

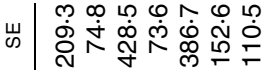

ฮ $\cos \cos \overline{0} \overline{0}=\cos 5 \frac{T}{0}$

$\sum$ 䎡

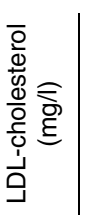

山

-

『্

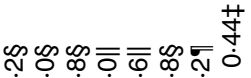

ஸ் ஸ் ڤ்

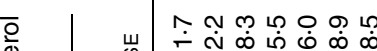

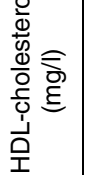

山)

đ

coscosio $\cos \overline{0} \overline{0}$

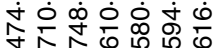

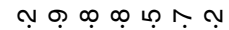

山

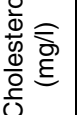

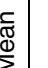

⿻ cos cos

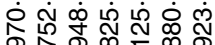

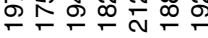

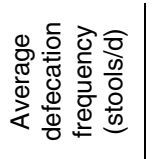

س

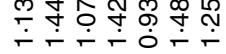

ㄴำ ำำำำำ

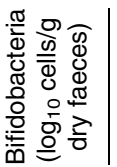

虫

ódóóó

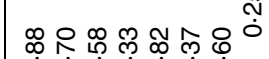

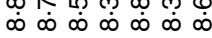

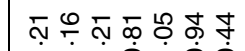

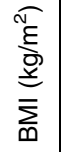

๘

용ㅇㅇㅇㅇㅇㅇ

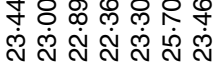

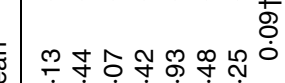

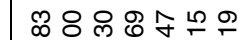

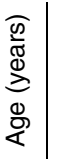

菂

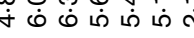

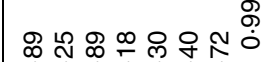

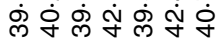

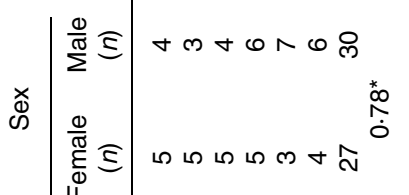

近

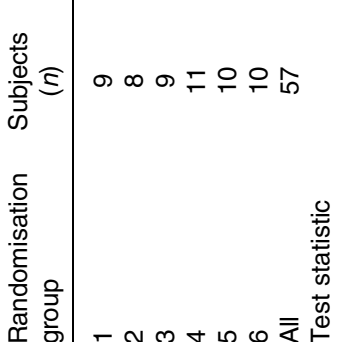

A second analysis of the clinical blood parameters was performed as defined for the efficacy analysis, but applied to the safety population (Table 3 ).

Conditional $F$ tests showed overall WBE-related significant treatment effects for four parameters: platelet count, lymphocyte percentage, mean corpuscular volume and bicarbonate $(P<0 \cdot 1)$. Subsequent pairwise comparisons demonstrated that the only parameter that was affected by WBE treatment as compared with placebo treatment was the lymphocyte percentage in plasma. Lymphocyte percentage was significantly lower after treatment with WBA at $3 \mathrm{~g} / \mathrm{d}(34.3 \%)$ than after the placebo treatment period $(36 \cdot 2 \%)(P=0.045)$. However, the lymphocyte percentage in plasma after treatment with WBA at $10 \mathrm{~g} / \mathrm{d}(33.8 \%)$ was not significantly different from the lymphocyte percentage in plasma after the placebo treatment period $(P>0 \cdot 1)$

\section{Analysis of efficacy variables}

Conditional $F$ tests showed overall WBE-related significant treatment effects for ten parameters (Table 4): level of bifidobacteria in faeces, percentage of bifidobacteria in faeces, level of Roseburia-E. rectale in faeces, faecal levels of acetic acid, propionic acid, butyric acid and total SCFA, stool $\mathrm{pH}$, percentage stool moisture and urinary $p$-cresol levels $(P<0 \cdot 1)$. The main results of the subsequent pairwise comparisons of these parameters will be discussed below.

\section{Levels of faecal microbiota}

In the PP population, WBE intake selectively increased bifidobacteria levels in the faeces (Table 4). Intake of WBE at $10 \mathrm{~g} / \mathrm{d}$ increased the average levels of bifidobacteria in the faeces relative to placebo intake by $0.36 \mathrm{log}$ units $(P<0.001)$. The average percentage of bifidobacteria relative to the total bacterial content in faeces upon intake of $10 \mathrm{~g}$ WBE/d increased by over 2-fold relative to placebo intake $(P<0.001)$, while intake of WBE at $3 \mathrm{~g} / \mathrm{d}$ tended to increase the average percentage of bifidobacteria by $1 \cdot 3$-fold $(P=0.065)$. The faecal levels of Roseburia-E. rectale group remained unchanged after WBE intake, as were the faecal levels of total bacteria, lactobacilli, $F$. prausnitzii and the C. histolyticum-lituseburense group.

\section{Biochemical parameters in faeces}

Intake of WBE at $10 \mathrm{~g} / \mathrm{d}$ increased the total level of faecal SCFA and the levels of acetic acid, propionic acid and butyric acid by about $8 \%$ relative to placebo intake $(P \leq 0.05)$ (Table 4). Additionally, at the dose of $3 \mathrm{~g} / \mathrm{d}$, WBE significantly increased faecal propionic acid levels $(P=0 \cdot 037)$. Consistently with the increased faecal SCFA levels, stool $\mathrm{pH}$ after intake of WBE at $10 \mathrm{~g} / \mathrm{d}(\mathrm{pH}=6.93)$ was significantly lower as compared with the stool $\mathrm{pH}$ after placebo intake $(\mathrm{pH}=7 \cdot 10)$ $(P=0.039)$.

WBE intake did not affect the percentage moisture in faeces, nor did it influence faecal ammonia levels $(P>0 \cdot 1)$. 
Table 3. Haematological and clinical blood chemistry parameters during a human intervention study following intake of placebo, wheat bran extract (WBE) at $3 \mathrm{~g} / \mathrm{d}$ or WBE at $10 \mathrm{~g} / \mathrm{d}$

(Mean values and standard deviations)

\begin{tabular}{|c|c|c|c|c|c|c|c|c|c|c|}
\hline & \multicolumn{2}{|c|}{$\begin{array}{l}\text { Placebo treat- } \\
\text { ment period }\end{array}$} & \multicolumn{2}{|c|}{$\begin{array}{l}3 \mathrm{~g} \mathrm{WBE} / \mathrm{d} \text { treat- } \\
\text { ment period }\end{array}$} & \multicolumn{2}{|c|}{$\begin{array}{c}10 \mathrm{~g} \mathrm{WBE} / \mathrm{d} \\
\text { treatment period }\end{array}$} & \multicolumn{4}{|c|}{$P^{*}$} \\
\hline & Mean & SD & Mean & SD & Mean & SD & $P 1$ & $P 2$ & P3 & $P 4$ \\
\hline \multicolumn{11}{|l|}{ Haematological parameters } \\
\hline Platelets $\left(10^{9} /\right)$ & $239 \cdot 7$ & $34 \cdot 8$ & $246 \cdot 4$ & $48 \cdot 2$ & $235 \cdot 0$ & $40 \cdot 8$ & 0.064 & 0.926 & 0.207 & 0.974 \\
\hline Eosinophils (\%) & 2.9 & $2 \cdot 2$ & 3.4 & 2.4 & 3.0 & 2.4 & 0.764 & 0.723 & 0.995 & 0.795 \\
\hline Packed cell volume & 0.4 & 0.0 & 0.4 & 0.0 & 0.4 & 0.0 & 0.826 & 0.869 & 0.871 & 1.000 \\
\hline $\mathrm{Hb}(\mathrm{g} / \mathrm{l})$ & 142 & 10 & 141 & 12 & 142 & 13 & 0.729 & 0.759 & 0.819 & 0.995 \\
\hline Lymphocytes (\%) & $36 \cdot 2$ & $9 \cdot 4$ & $34 \cdot 3$ & $7 \cdot 8$ & 33.8 & 8.9 & 0.056 & 0.187 & 0.739 & 0.045 \\
\hline $\mathrm{MCH}(\mathrm{pg})$ & $29 \cdot 3$ & 1.5 & 29.5 & 1.5 & $29 \cdot 6$ & $1 \cdot 3$ & 0.126 & 0.728 & 0.355 & 0.101 \\
\hline $\mathrm{MCHC}(\mathrm{g} / \mathrm{l})$ & 327 & 10 & 327 & 9 & 329 & 8 & 0.843 & 1.000 & 0.999 & 0.901 \\
\hline $\operatorname{MCV}(\mathrm{fl})$ & 89.5 & $4 \cdot 1$ & $90 \cdot 1$ & 4.6 & $90 \cdot 1$ & $4 \cdot 1$ & 0.039 & 1.000 & 0.902 & 0.689 \\
\hline Monocytes (\%) & 8.2 & $2 \cdot 1$ & $8 \cdot 7$ & $2 \cdot 0$ & 8.5 & 1.7 & 0.603 & 0.606 & 0.994 & 0.695 \\
\hline MPV (fl) & 10.5 & 0.8 & 10.5 & 0.9 & $10 \cdot 6$ & 0.9 & 0.770 & 0.859 & 0.716 & 0.967 \\
\hline Erythrocyte count $\left(10^{9} / /\right)$ & 4.9 & 0.4 & 4.8 & 0.5 & $4 \cdot 8$ & 0.5 & 0.559 & 0.898 & 0.507 & 0.796 \\
\hline Erythrocyte distribution width (\%) & $13 \cdot 0$ & 0.6 & $13 \cdot 1$ & 0.8 & $13 \cdot 1$ & 0.8 & 0.574 & 0.568 & 0.656 & 0.991 \\
\hline Leucocyte count $\left(10^{9} / /\right)$ & $5 \cdot 7$ & 1.5 & $5 \cdot 6$ & 1.4 & $5 \cdot 7$ & 1.6 & 0.861 & 0.872 & 0.998 & 0.906 \\
\hline \multicolumn{11}{|l|}{ Clinical chemistry parameters } \\
\hline Glucose (mg/l) & 853 & 80 & 862 & 93 & 879 & 89 & 0.353 & 0.385 & 0.442 & 0.995 \\
\hline Insulin (nм) & 38.4 & $19 \cdot 2$ & 41.4 & $22 \cdot 2$ & $40 \cdot 8$ & 21.6 & 0.400 & 0.935 & 0.560 & 0.377 \\
\hline $\mathrm{Ca}(\mathrm{mg} / \mathrm{l})$ & 92 & 4 & 93 & 4 & 93 & 5 & 0.324 & 0.997 & 1.000 & 0.881 \\
\hline $\mathrm{Cl}(\mathrm{mm})$ & $104 \cdot 0$ & $2 \cdot 1$ & $104 \cdot 3$ & $2 \cdot 2$ & 104.4 & $2 \cdot 0$ & 0.579 & 0.572 & 0.992 & 0.672 \\
\hline $\mathrm{Fe}(\mu \mathrm{g} / \mathrm{l})$ & 1164 & 416 & 1028 & 444 & 1017 & 371 & 0.244 & 0.241 & 0.865 & 0.549 \\
\hline $\mathrm{K}(\mathrm{mM})$ & 4.0 & 0.5 & 4.1 & 0.5 & $4 \cdot 1$ & 0.4 & 0.485 & 0.641 & 0.872 & 0.375 \\
\hline $\mathrm{Mg}(\mathrm{mg} / \mathrm{l})$ & 22 & 1 & 22 & 1 & 22 & 1 & 0.957 & 0.960 & 0.982 & 0.996 \\
\hline $\mathrm{Na}(\mathrm{mm})$ & $141 \cdot 1$ & 1.5 & $141 \cdot 8$ & $2 \cdot 1$ & 140.7 & 1.8 & 0.168 & 0.678 & 0.157 & 0.587 \\
\hline Phosphate $(\mathrm{mg} / \mathrm{l})$ & 28 & 6 & 29 & 6 & 30 & 5 & 0.614 & 0.997 & 1.000 & 0.999 \\
\hline Bicarbonate $(\mathrm{mM})$ & $25 \cdot 6$ & $2 \cdot 1$ & $25 \cdot 8$ & 1.8 & $25 \cdot 0$ & $2 \cdot 1$ & 0.026 & 0.405 & 0.019 & 0.344 \\
\hline Cholesterol (mg/l) & 1908 & 313 & 1931 & 342 & 1928 & 402 & 0.415 & 0.591 & 0.777 & 0.247 \\
\hline HDL-cholesterol (mg/l) & 649 & 220 & 626 & 187 & 633 & 177 & 0.980 & 0.987 & 0.999 & 0.992 \\
\hline LDL-cholesterol (mg/l) & 1083 & 269 & 1127 & 302 & 1116 & 363 & 0.137 & 0.237 & 0.760 & 0.078 \\
\hline TAG (mg/l) & 881 & 423 & 888 & 555 & 893 & 490 & 0.640 & 0.629 & 0.900 & 0.892 \\
\hline NEFA (mм) & 0.5 & 0.3 & 0.4 & 0.2 & 0.4 & 0.2 & 0.754 & 0.947 & 0.982 & 1.000 \\
\hline$\gamma$-Glutamyltransferase $(\mathrm{U} / \mathrm{I})$ & $22 \cdot 6$ & $16 \cdot 2$ & $19 \cdot 3$ & $8 \cdot \overline{7}$ & 22.9 & $15 \cdot \overline{9}$ & 0.701 & 0.964 & 0.609 & 0.776 \\
\hline Lactate dehydrogenase (U/I) & 362.6 & $63 \cdot 6$ & 363.6 & 50.5 & 364.6 & $52 \cdot 8$ & 0.112 & 0.505 & 0.492 & 0.076 \\
\hline Phosphatase (U/I) & $149 \cdot 4$ & $42 \cdot 8$ & 151.4 & $38 \cdot 0$ & $155 \cdot 3$ & $40 \cdot 6$ & 0.651 & 0.811 & 0.999 & 0.808 \\
\hline Alanine aminotransferase $(\mathrm{U} / \mathrm{l})$ & $22 \cdot 2$ & $9 \cdot 8$ & $21 \cdot 0$ & $7 \cdot 3$ & $21 \cdot 0$ & $10 \cdot 4$ & 0.187 & 0.773 & 0.149 & 0.478 \\
\hline Amylase (U/l) & $76 \cdot 6$ & $29 \cdot 8$ & $76 \cdot 6$ & $29 \cdot 4$ & $76 \cdot 6$ & $31 \cdot 3$ & 0.430 & 0.724 & 0.441 & 0.893 \\
\hline Aspartate aminotransferase (U/I) & $23 \cdot 8$ & $4 \cdot 0$ & 23.9 & $4 \cdot 8$ & 23.8 & 6.4 & 0.914 & 0.920 & 0.998 & 0.900 \\
\hline Creatine kinase (U/l) & $105 \cdot 2$ & 45.5 & $108 \cdot 9$ & $58 \cdot 3$ & 111.6 & $76 \cdot 2$ & 0.881 & 0.937 & 0.969 & 0.841 \\
\hline Lipase (U/I) & 33.6 & $7 \cdot 8$ & 32.9 & 7.7 & $32 \cdot 8$ & $10 \cdot 0$ & 0.557 & 0.554 & 0.935 & 0.789 \\
\hline Folate $(\mu \mathrm{g} / \mathrm{l})$ & 9.9 & $3 \cdot 2$ & 9.4 & $3 \cdot 2$ & 9.4 & 3.0 & 0.117 & 0.474 & 0.502 & 0.070 \\
\hline Vitamin A $(\mu \mathrm{g} / \mathrm{l})$ & $597 \cdot 3$ & $163 \cdot 6$ & 574.4 & $142 \cdot 5$ & $582 \cdot 4$ & 131.4 & 0.623 & 0.980 & 1.000 & 1.000 \\
\hline Albumin ( $\mathrm{g} / \mathrm{l})$ & $47 \cdot 3$ & $2 \cdot 7$ & $47 \cdot 2$ & 3.0 & $47 \cdot 1$ & 2.9 & 0.967 & 0.987 & 0.991 & 1.000 \\
\hline Bilirubin (mg/l) & 7 & 3 & 6 & 3 & 6 & 3 & 0.431 & 0.418 & 0.894 & 0.722 \\
\hline Total protein $(\mathrm{g} / \mathrm{l})$ & $77 \cdot 7$ & 3.9 & 78.2 & $4 \cdot 3$ & 77.4 & 4.5 & 0.529 & 0.981 & 0.582 & 0.486 \\
\hline Uric acid (mg/l) & 50 & 11 & 49 & 11 & 49 & 10 & 0.995 & 1.000 & 0.995 & 0.994 \\
\hline Creatinine $(\mathrm{mg} / \mathrm{l})$ & 9 & 2 & 8 & 2 & 8 & 2 & 0.821 & 0.770 & 0.840 & 0.993 \\
\hline Urea $(\mathrm{mg} / \mathrm{l})$ & 323 & 76 & 322 & 79 & 332 & 79 & 0.861 & 0.836 & 1.000 & 0.833 \\
\hline
\end{tabular}

$\mathrm{MCH}$, mean corpuscular $\mathrm{Hb}$; MCHC, mean corpuscular $\mathrm{Hb}$ concentration; MCV, mean corpuscular volume; MPV, mean platelet volume.

${ }^{*} P 1$ is the $P$ value of the conditional $F$ test for overall WBE-related significant treatment effects; $P 2, P 3$ and $P 4$ are the $P$ values for the comparison between WBE at $10 \mathrm{~g} / \mathrm{d}$ and placebo, WBE at $10 \mathrm{~g} / \mathrm{d}$ and WBE at $3 \mathrm{~g} / \mathrm{d}$, and WBE at $3 \mathrm{~g} / \mathrm{d}$ and placebo, respectively.

\section{Urinary and serum levels of phenolic compounds}

The completeness of each urine collection was estimated from the calculation of the observed:expected creatinine ratio as proposed by Knuiman et al. ${ }^{(34)}$. Of the 188 urine collections, thirty-one were classified as incomplete and were not taken into account for the statistical analysis of $p$-cresol and phenol excretion. Table 4 shows the effects of WBE and placebo intake on the urinary levels of phenolic compounds. In general, $p$-cresol levels were about four times higher than phenol levels. WBE intake at the dose of $10 \mathrm{~g} / \mathrm{d}$ decreased urinary $p$-cresol levels by $37 \%(P=0.031)$. WBE intake did not influence urinary phenol excretion $(P>0 \cdot 1)$.

Average serum levels of $p$-cresylsulfate varied between 12.2 and $15.8 \mu \mathrm{m}$. WBE intake did not influence the serum $p$-cresylsulfate levels $(P>0 \cdot 1)$.

\section{Energy intake}

In the PP population, WBE intake did not modulate the average daily energy intake, or the average percentage of energy from carbohydrates, lipids or proteins $(P \geq 0 \cdot 1)$. 
Table 4. Efficacy variables during a human intervention study following intake of placebo, wheat bran extract (WBE) at $3 \mathrm{~g} / \mathrm{d}$ or WBE at $10 \mathrm{~g} / \mathrm{d}$ (Mean values and standard deviations)

\begin{tabular}{|c|c|c|c|c|c|c|c|c|c|c|}
\hline & \multicolumn{2}{|c|}{$\begin{array}{l}\text { Placebo treatment } \\
\text { period }\end{array}$} & \multicolumn{2}{|c|}{$\begin{array}{c}3 \mathrm{~g} \mathrm{WBE} / \mathrm{d} \text { treatment } \\
\text { period }\end{array}$} & \multicolumn{2}{|c|}{$\begin{array}{l}10 \mathrm{~g} \mathrm{WBE} / \mathrm{d} \text { treat- } \\
\text { ment period }\end{array}$} & \multicolumn{4}{|c|}{$P^{*}$} \\
\hline & Mean & SD & Mean & SD & Mean & SD & $P 1$ & P2 & P3 & $P 4$ \\
\hline \multicolumn{11}{|l|}{ Dietary analysis } \\
\hline \multicolumn{11}{|l|}{ Energy intake } \\
\hline $\mathrm{kJ}$ & 9478.4 & $2676 \cdot 5$ & $10047 \cdot 5$ & $2756 \cdot 0$ & $9857 \cdot 1$ & $2604 \cdot 1$ & 0.117 & 0.357 & 0.770 & 0.099 \\
\hline kcal & 2265.4 & 639.7 & 2401.4 & 658.7 & 2355.9 & 622.4 & 0.117 & 0.357 & 0.770 & 0.099 \\
\hline$\%$ Energy from proteins & 14.9 & 3.6 & 14.5 & 3.3 & 14.5 & $3 \cdot 3$ & 0.690 & 0.991 & 0.999 & 0.985 \\
\hline$\%$ Energy from carbohydrates & $47 \cdot 3$ & $8 \cdot 0$ & 48.4 & 7.9 & 48.4 & $8 \cdot 1$ & 0.432 & 0.510 & 0.999 & 0.487 \\
\hline$\%$ Energy from lipids & $32 \cdot 7$ & 7.5 & $32 \cdot 0$ & 7.3 & $32 \cdot 0$ & $6 \cdot 7$ & 0.745 & 0.774 & 0.999 & 0.794 \\
\hline \multicolumn{11}{|l|}{ Levels of faecal microbiota } \\
\hline Total bacteria $\left(\log _{10}\right.$ cells/g dry faeces) & $10 \cdot 9$ & 0.3 & $10 \cdot 7$ & 0.3 & $10 \cdot 8$ & 0.4 & 0.140 & 1.000 & 0.889 & 0.657 \\
\hline Bifidobacteria ( $\log _{10}$ cells/g dry faeces) & 8.9 & 0.6 & $9 \cdot 0$ & 0.5 & $9 \cdot 3$ & 0.7 & 0.000 & 0.000 & 0.041 & 0.603 \\
\hline Percentage bifidobacteria & $2 \cdot 4$ & $3 \cdot 2$ & 3.3 & 3.6 & $5 \cdot 1$ & 4.3 & 0.000 & 0.000 & 0.004 & 0.065 \\
\hline Lactobacilli ( $\log _{10}$ cells/g dry faeces) & 5.7 & $2 \cdot 2$ & 5.9 & $2 \cdot 2$ & 5.4 & $2 \cdot 3$ & 0.962 & 1.000 & 1.000 & 1.000 \\
\hline Faecalibacterium prausnitzii ( $\log _{10}$ cells/g dry faeces) & 9.4 & 0.6 & $9 \cdot 4$ & 0.4 & 9.4 & 0.5 & 0.642 & 0.749 & 0.632 & 0.966 \\
\hline Clostridium histolyticum-lituseburense ( $\log _{10}$ cells/g dry faeces) & $3 \cdot 2$ & $1 \cdot 2$ & 3.7 & $2 \cdot 0$ & $3 \cdot 6$ & 1.8 & 0.187 & 0.450 & 0.850 & 0.220 \\
\hline Roseburia-Eubacterium rectale $\left(\log _{10}\right.$ cells/g dry faeces) & 9.4 & 0.9 & 9.5 & 0.4 & 9.5 & 0.5 & 0.050 & 1.000 & 1.000 & 1.000 \\
\hline \multicolumn{11}{|l|}{ Biochemical parameters of faeces } \\
\hline Acetic acid ( $\mu \mathrm{mol} / \mathrm{g}$ dry faeces) & 454.9 & $415 \cdot 7$ & $463 \cdot 8$ & 336.6 & 493.4 & $265 \cdot 3$ & 0.007 & 0.003 & 0.193 & 0.281 \\
\hline Propionic acid ( $\mu \mathrm{mol} / \mathrm{g}$ dry faeces) & $106 \cdot 3$ & 88.7 & $109 \cdot 2$ & 64.6 & $116 \cdot 0$ & 73.4 & 0.010 & 0.009 & 0.882 & 0.037 \\
\hline Butyric acid ( $\mu \mathrm{mol} / \mathrm{g}$ dry faeces) & $103 \cdot 0$ & $104 \cdot 3$ & $99 \cdot 1$ & 73.5 & $108 \cdot 0$ & $75 \cdot 6$ & 0.069 & 0.050 & 0.651 & 0.308 \\
\hline Total SCFA ( $\mu \mathrm{mol} / \mathrm{g}$ dry faeces) & $664 \cdot 3$ & $570 \cdot 1$ & $672 \cdot 1$ & 451.9 & $717 \cdot 4$ & $381 \cdot 2$ & 0.003 & 0.001 & 0.251 & 0.130 \\
\hline Stool pH & $7 \cdot 1$ & 0.6 & $7 \cdot 0$ & 0.5 & 6.9 & 0.5 & 0.053 & 0.039 & 0.587 & 0.311 \\
\hline Moisture (\%) & $71 \cdot 2$ & 7.9 & $72 \cdot 1$ & $6 \cdot 7$ & $73 \cdot 0$ & $6 \cdot 4$ & 0.081 & 0.112 & 0.996 & 0.135 \\
\hline Ammonia (mg/g dry faeces) & $2 \cdot 1$ & 0.9 & $2 \cdot 1$ & 1.0 & $2 \cdot 3$ & $1 \cdot 1$ & 0.858 & 0.722 & 0.986 & 0.813 \\
\hline \multicolumn{11}{|l|}{ Levels of phenolic compounds } \\
\hline Urinary $p$-cresol (mg/g creatinine) & 34.2 & $36 \cdot 0$ & $29 \cdot 1$ & $26 \cdot 7$ & $21 \cdot 6$ & $18 \cdot 9$ & 0.034 & 0.031 & 0.139 & 0.843 \\
\hline Urinary phenol (mg/g creatinine) & $7 \cdot 3$ & 9.9 & 4.9 & $2 \cdot 3$ & $5 \cdot 1$ & $3 \cdot 3$ & 0.829 & 0.783 & 0.905 & 0.973 \\
\hline Serum $p$-cresylsulfate $(\mu \mathrm{M})$ & $15 \cdot 0$ & $12 \cdot 2$ & $16 \cdot 2$ & $14 \cdot 3$ & $12 \cdot 6$ & $11 \cdot 1$ & 0.203 & 0.220 & 0.315 & 0.976 \\
\hline \multicolumn{11}{|l|}{ Bowel habits } \\
\hline Defecation frequency (no. bowel movements/d) & 1.3 & 0.6 & 1.3 & 0.4 & 1.3 & 0.5 & 0.258 & 0.224 & 0.750 & 0.623 \\
\hline Stool consistency (average stool consistency/bowel movement) & 3.8 & $1 \cdot 1$ & 3.8 & 1.0 & 3.8 & 0.9 & 0.815 & 0.863 & 0.828 & 0.997 \\
\hline Bristol composite measure (average stool consistency/d) & 3.4 & $1 \cdot 3$ & 3.4 & 1.1 & 3.4 & $1 \cdot 1$ & 0.956 & 0.956 & 0.889 & 0.983 \\
\hline \multicolumn{11}{|l|}{ Blood lipids } \\
\hline Cholesterol (mg/l) & 1901 & 309 & 1921 & 351 & 1925 & 404 & 0.474 & 0.553 & 0.924 & 0.362 \\
\hline HDL-cholesterol (mg/l) & 614 & 159 & 601 & 166 & 615 & 163 & 0.976 & 0.994 & 0.981 & 0.996 \\
\hline LDL-cholesterol (mg/l) & 1105 & 272 & 1141 & 314 & 1130 & 371 & 0.168 & 0.258 & 0.885 & 0.122 \\
\hline TAG (mg/l) & 909 & 433 & 895 & 577 & 902 & 503 & 0.597 & 0.613 & 0.949 & 0.820 \\
\hline
\end{tabular}

${ }^{*} P 1$ is the $P$ value of the conditional $F$ test for overall WBE-related significant treatment effects; $P 2, P 3$ and $P 4$ are the $P$ values for the comparison between WBE at $10 \mathrm{~g} / \mathrm{d}$ and placebo, WBE at $10 \mathrm{~g} / \mathrm{d}$ and WBE at $3 \mathrm{~g} / \mathrm{d}$, and WBE at $3 \mathrm{~g} / \mathrm{d}$ and placebo, respectively. 


\section{Blood lipids}

In the PP population, WBE intake did not affect the average blood levels of either total cholesterol, LDL-cholesterol, HDL-cholesterol or TAG $(P>0 \cdot 1)$.

\section{Bowel habits: defecation frequency and stool consistency}

WBE intake did not influence the number of bowel movements per $\mathrm{d}$, nor did it modulate stool consistency as measured using the Bristol Stool Form Scale $(P>0 \cdot 1)$.

\section{Analysis of tolerability}

Tolerability was assessed through self-reported scoring by the volunteers of the occurrence frequency and distress severity of eighteen different gastrointestinal symptoms. During treatment with WBA at $10 \mathrm{~g} / \mathrm{d}$, both the occurrence frequency and distress severity of flatulence increased compared with the placebo treatment $(P=0 \cdot 02$, binary mixed model; $P<0 \cdot 05$, Bayesian ordinal mixed model) (Fig. 3(a) and (b)). With respect to occurrence frequency, the largest increase was seen in the
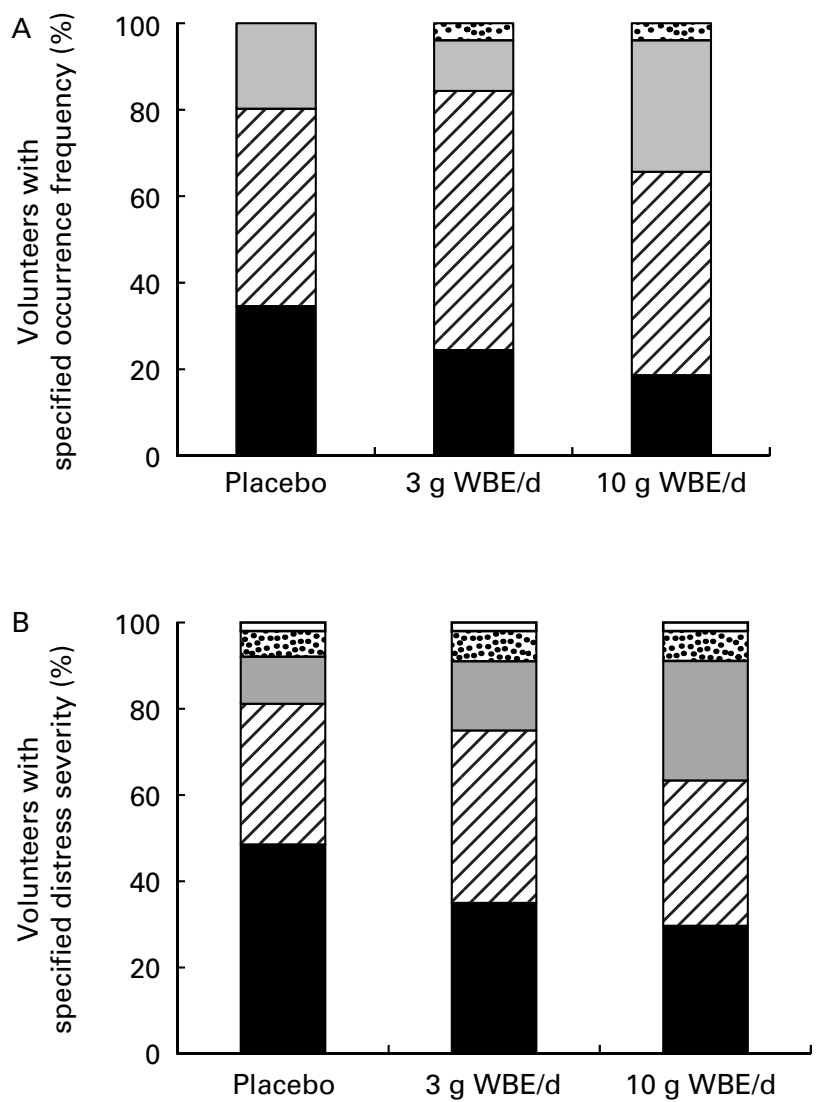

Fig. 3. (a) Distribution of flatulence occurrence frequency scores. ( $\square$ ) Frequency 0 (never); $(\square)$, frequency $>0-1 ;(\square)$, frequency $>1-2$; (因), frequency $>2-3$. Frequency 1 , occasionally; frequency 2 , regularly; frequency 3 , nearly always; WBE, wheat bran extract. (b) Distribution of flatulence distress severity scores. ( $\square$ ), Score 0 (not disturbing); $(\square)$, score $>0-1$; $(\square)$, score $>1-2$; (因), score $>2-3$; $(\square)$, score $>3-4$. Score 1 , minimally disturbing; score 2, mildly disturbing; score 3, moderately disturbing; score 4, very disturbing.

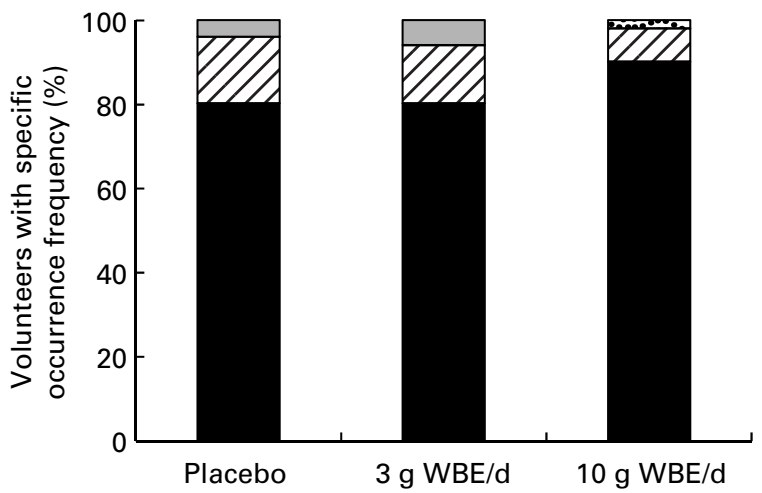

Fig. 4. Distribution of constipation occurrence frequency scores. (ם) Frequency 0 (never); $(\nabla)$, frequency $>0-1 ;(\square)$, frequency $>1-2 ;($ 因), frequency $>2-3$. Frequency 1 , occasionally; frequency 2 , regularly; frequency 3 , nearly always; WBE, wheat bran extract.

scores ranging between occasionally and regularly, while no increases were seen in the more severe flatulence occurrence frequency scores. With respect to distress severity, the largest increase was seen in the scores ranging between minimally disturbing and mildly disturbing. A slight reduction in occurrence frequency of constipation was observed upon intake of WBE at $10 \mathrm{~g} / \mathrm{d}$ compared with placebo intake $(P=0.095$; binary mixed model) (Fig. 4). The subjects that never experienced constipation increased from $81 \%$ during the placebo treatment period to $91 \%$ during treatment with WBA at $10 \mathrm{~g} / \mathrm{d}$ $(P=0.095$; binary mixed model). None of the other assessed gastrointestinal symptoms was affected by WBE intake.

\section{Discussion}

WBE consumption during 3 weeks at a daily dosage of $10 \mathrm{~g}$ led to an increase in bifidobacteria counts relative to placebo intake. Cloetens et al. ${ }^{(10)}$ previously showed that the stimulation of bifidobacteria after WBE intake was most pronounced in subjects with the lowest baseline levels. Since bifidobacteria levels have been shown to decrease upon ageing $^{(57,58)}$, we determined the effect of age on faecal bifidobacteria levels in two age subgroups: 18- to 50-year subgroup and $\geq 51$-year subgroup. This analysis showed that intake of WBE at $10 \mathrm{~g} / \mathrm{d}$ significantly $(P<0.05)$ increased faecal bifidobacteria in both age subgroups (data not shown). In addition, a statistically significant increase $(P<0.05)$ in bifidobacteria was found regardless of sex (data not shown).

It is well known that the prebiotic effect of a compound is strongly affected by the baseline levels of targeted beneficial bacteria in faeces, in the sense that relatively lower relative changes are observed upon intake of a prebiotic compound when the baseline levels are high ${ }^{(59,60)}$. Since the baseline level of faecal bifidobacteria in the present study was already high ( $\log _{10} 8.6$ cells/g dry faeces), it is not surprising that the relative increase in faecal levels of bifidobacteria is relatively small. In addition, the change in absolute numbers of beneficial intestinal bacteria is considered to be more important for the prebiotic effect than the relative change ${ }^{(60,61)}$. The $0.4 \mathrm{log}$ increase in faecal bifidobacteria levels after 
intake of WBE observed in the present study amounts to an increase by an absolute number of about $2 \times 10^{9}$ cells/g dry faeces, which is in the same order of magnitude observed in several other studies reviewed by Roberfroid et al. ${ }^{(60)}$.

We demonstrated that the total levels of faecal SCFA and of the individual SCFA, acetic acid, propionic acid and butyric acid, were increased upon intake of WBE at $10 \mathrm{~g} / \mathrm{d}$ relative to placebo intake, while an increase of faecal propionic acid levels already occurred upon intake of WBE at $3 \mathrm{~g} / \mathrm{d}$. WBE appears to increase the faecal level of SCFA at lower doses than reported for other prebiotic compounds such as inulin and oligofructose. A number of studies in human volunteers who consumed oligofructose at high dosages varying from 13 to $20 \mathrm{~g} / \mathrm{d}$ revealed an increase in faecal concentrations of acetic $\operatorname{acid}^{(62)}$ or total SCFA, acetic acid and propionic $\operatorname{acid}^{(63)}$, but not in butyric acid ${ }^{(62,63)}$. However, consumption of $20-40 \mathrm{~g}$ inulin/d was reported not to modulate faecal levels of SCFA in a statistically significant way ${ }^{(64-66)}$. Additionally, Gibson et al. could not demonstrate an increase in faecal SCFA levels after consumption of $15 \mathrm{~g}$ oligofructose $/ \mathrm{d}^{(67)}$. The increased levels of bifidobacteria in the faeces could explain the increased faecal acetic acid levels after WBE intake as compared with placebo intake. In fact, in vitro studies have demonstrated that different Bifidobacterium sp. can degrade AXOS, thereby generating SCFA, mainly acetate and the organic acid lactate ${ }^{(6,68)}$. Bifidobacteria do not produce butyric acid and a mechanism of cross-feeding with acetate- or lactateconverting bacteria may be involved in increased colonic butyric acid production ${ }^{(69,70)}$. The levels of bacteria of the Roseburia-E. rectale group and of the $F$. prausnitzii group were determined given their butyric acid-producing capacity $^{(71)}$. WBE intake did not increase faecal levels of the Roseburia-E. rectale group or of the Faecalibacterium group. However, the metabolic activity of the Roseburia-E. rectale group or the Faecalibacterium group could be changed upon WBE administration, leading to an increase in butyric acid-forming capacity, which cannot be detected using FISH. In addition, using a new molecular approach, based on analysis of the butytyl-CoA:acetate CoA transferase gene, Louis et al. identified twenty novel operational taxonomic units probably capable of producing butyrate ${ }^{(72)}$. Hence, the observed increase in butyrate production upon WBE intake could be explained by an increase in the levels of novel, still to be identified, butyrate-producing strains. The ability of the different members of the gut community to compete successfully depends on many traits besides their ability to utilise certain substrates, such as their intrinsic growth rate, tolerance to colonic $\mathrm{pH}$ fluctuations and efficient binding to substrate particles and gut surfaces ${ }^{(72)}$.

Concomitant with the increased SCFA production, intake of WBE at $10 \mathrm{~g} / \mathrm{d}$ significantly decreased stool $\mathrm{pH}$ by about $0 \cdot 2$ units as compared with placebo intake. A more acidic gut environment is reported to enhance the colonisation resistance against pathogens ${ }^{(73)}$, to reduce the formation of secondary bile acids ${ }^{(74)}$ and to impair the activity of specific enzymes such as proteases ${ }^{(75)}$.

Intake of WBE at $10 \mathrm{~g} / \mathrm{d}$ resulted in a marked reduction of urinary $p$-cresol levels by $37 \%$ as compared with the $p$-cresol levels after placebo intake, which is indicative for a reduction in colonic protein fermentation. The reduction observed in the present study confirms previous results ${ }^{(10)}$ and is in agreement with foregoing studies in which a beneficial modulation of the colonic ammonia metabolism (another protein fermentation metabolite) was observed after AXOS intake ${ }^{(36)}$. Colonic fermentation of proteins results in the formation of ammonia, nitrosamines, thiols and phenolic compounds, which are generally believed to be potentially harmful. Hence, reduction of colonic protein fermentation is believed to be beneficial to human health ${ }^{(19)}$

Besides a small difference for lymphocyte percentage, we found no difference in any of forty-four safety-related blood parameters that were tested following WBE intake. The difference in lymphocytes was not considered toxicologically relevant since the observed difference was within the normal range and not dose-dependent, and since WBE intake did not affect the occurrence of adverse blood shifts in this or any other blood parameter. Absence of adverse effects on blood parameters was previously observed in a smaller-scale intervention trial on healthy subjects with WBE-like material ${ }^{(10)}$.

Intake of WBE at doses up to $10 \mathrm{~g} / \mathrm{d}$ did not affect bowel habits. This is in agreement with a study in which intake of inulin at $20 \mathrm{~g} / \mathrm{d}$ by healthy volunteers did not modulate stool frequency and consistency ${ }^{(65)}$. In addition, intake of WBE at doses up to $10 \mathrm{~g} / \mathrm{d}$ had no effect on most of the eighteen gastrointestinal symptoms surveyed. A mild increase of flatulence was observed at intake of WBE at $10 \mathrm{~g} / \mathrm{d}$. Mild to moderate flatulence was observed in some studies with other prebiotic compounds such as inulin and fructo-oligosaccharides, which is caused by the production of gases upon fermentation of the prebiotic compound ${ }^{(34,65,76-79)}$. On the other hand, a trend of decreased occurrence frequency of constipation was noted at the high WBE dose. Improvement of constipation symptoms has been observed for other prebiotic compounds, such as xylo-oligosaccharides $^{(80)}$ and inulin ${ }^{(66,81,82)}$, yet these studies were generally performed on constipated subjects.

The low incidence of gastrointestinal complaints and the absence of adverse changes in haematology and clinical blood chemistry parameters provide evidence for the excellent tolerability and safety of WBE, complementing the results of the in vitro and in vivo safety assessment of $\mathrm{WBE}^{(83)}$.

We recommend that WBE should be taken in at the dose of $10 \mathrm{~g} / \mathrm{d}$, considering that consumption of WBE at this dosage exerts the following beneficial effects on gut health parameters: increased production of SCFA, reduction of protein fermentation and increase of faecal bifidobacteria levels. Moreover, WBE is well tolerated and does not cause adverse effects at up to $10 \mathrm{~g} / \mathrm{d}$ in healthy adult volunteers.

\section{Acknowledgements}

The authors thank Jan Wijffels (BNOSAC - the Belgium Network of Open Source Analytical Consultants) for the statistical analysis. The authors are also grateful to Erwin Raangs for technical assistance in analysing the faecal microbiota. The authors' responsibilities were as follows: I. E. J. A. F., O. L., 
J. A. D., C. M. C., K. V. and W. F. B. conceived of and designed the study; W. S. V. coordinated the production of the study's soft drinks; M. M. and S. P. were responsible for the analysis of ammonia content in stool samples; P. E. was responsible for the analysis of $p$-cresylsulfate content in serum; H. H., E. $\mathrm{H}$. and $\mathrm{K}$. W. were responsible for the analysis of the percentage moisture in the faecal samples and for the analysis of $p$ cresol content in urine; G. W. W. was responsible for the analysis of microbiota levels in the faecal samples; I. E. J. A. F. and W. F. B. were responsible for interaction with Jan Wijffels for analysis of the data; I. E. J. A. F. and W. F. B. had full access to all of the data in the study and jointly take responsibility for its integrity; I. E. J. A. F., O. L. and W. F. B. wrote the paper. I. E. J. A. F., O. L., W. S. V. and W. F. B. are presently employed by Fugeia NV, which manufactures the wheat bran extract product and is the sole sponsor source of funding for the studies described in the present paper.

\section{References}

1. Swennen K, Courtin CM, Lindemans GCJE, et al. (2006) Large scale production and characterisation of wheat bran arabinoxylooligosaccharides. J Sci Food Agric 86, $1722-1731$.

2. Izydorczyk MS \& Biliaderis CG (1995) Cereal arabinoxylans: advances in structure and physicochemical properties. Carbohydr Polym 28, 33-48.

3. Schooneveld-Bergmans MEF, Beldman G \& Voragen AGJ (1999) Structural features of glucurono(arabinoxylans) extracted from wheat bran by barium hydroxide. I Cereal Sci 29, 63-75.

4. Andersson R \& Aman P. (2008) Cereal arabinoxylan: occurrence, structure and properties. In Advanced Dietary Fibre Technology, pp. 301-314 [BV McCleary and L Prosky, editors]. Oxford: Blackwell Science Ltd.

5. Femia AP, Salvadori M, Broekaert WF, et al. (2010) Arabinoxylan oligosaccharides (AXOS) reduce preneoplastic lesions in the colon of rats treated with 1,2-dimethylhydrazine (DMH). Eur J Nutr 49, 127-132.

6. Yamada H, Itoh K, Morishita Y, et al. (1993) Structure and properties of oligosaccharides from wheat bran. Cereal Food World 38, 490-492.

7. Courtin CM, Swennen K, Broekaert WF, et al. (2008) Dietary inclusion of wheat bran arabinoxylooligosaccharides has beneficial nutritional effects on chickens. Cereal Chem 85, 607-613.

8. Courtin CM, Swennen K, Broekaert WF, et al. (2008) Effects of dietary inclusion of xylooligosaccharides, arabinoxylooligosaccharides and soluble arabinoxylan on the microbial composition of caecal contents of chickens. J Sci Food Agric 88, 2517-2522.

9. Van Craeyveld V, Swennen K, Dornez E, et al. (2008) Structurally different wheat-derived arabinoxylooligosaccharides have different prebiotic and fermentation properties in rats. J Nutr 138, 2348-2355.

10. Cloetens L, Broekaert WF, Delaedt Y, et al. (2010) Tolerance of arabinoxylan-oligosaccharides and their prebiotic activity in healthy subjects: a randomised, placebo-controlled cross-over study. Br J Nutr 103, 703-713.

11. Broekaert WF, Courtin CM, Verbeke K, et al. (2011) Prebiotic and other health-related effects of cereal-derived arabinoxylans, arabinoxylan-oligosaccharides and xylo-oligosaccharides. Crit Rev Food Sci Nutr 51, 178-194.
12. Hamer HM, De Preter V, Cloetens L, et al. (2010) A dietary intervention with arabinoxylan oligosaccharides reduces colonic protein fermenation in heatlhy subjects: results from faecal metabolite fingerprint analysis. Gastroenterology 138, Suppl. 1, 616.

13. Hughes R, Magee EA \& Bingham S (2000) Protein degradation in the large intestine: relevance to colorectal cancer. Curr Issues Intest Microbiol 1, 51-58.

14. Bammens B, Evenepoel P, Keuleers H, et al. (2006) Free serum concentrations of the protein-bound retention solute p-cresol predict mortality in hemodialysis patients. Kidney Int 69, 1081-1087.

15. Muir JG, Walker KZ, Kaimakamis MA, et al. (1998) Modulation of fecal markers relevant to colon cancer risk: a high-starch Chinese diet did not generate expected beneficial changes relative to a Western-type diet. Am J Clin Nutr 68, 372-379.

16. Bone E, Tamm A \& Hill M (1976) Production of urinary phenols by gut bacteria and their possible role in causation of large bowel cancer. Am J Clin Nutr 29, 1448-1454.

17. De Graaf AA \& Venema K (2008) Gaining insight into microbial physiology in the large intestine: a special role for stable isotopes. Adv Microb Physiol 53, 73-168.

18. Meijers B, De Preter V, Verbeke K, et al. (2009) p-Cresyl sulfate serum concentratons in haemodialysis patients are reduced by the prebiotic oligofructose-enriched inulin. Nephrol Dial Transplant 25, 219-224.

19. De Preter V, Falony G, Windey K, et al. (2010) The prebiotic, oligofructose-enriched inulin modulates the faecal metabolite profile: an in vitro analysis. Mol Nutr Food Res 54 , 1791-1801.

20. Grootaert C, Delcour JA, Courtin CM, et al. (2007) Microbial metabolism and prebiotic potency of arabinoxylan oligosaccharides in the human intestine. Trends Food Sci Technol 18, $64-71$.

21. Sanchez JI, Marzorati M, Grootaert C, et al. (2009) Arabinoxylan-oligosaccharides (AXOS) affect the protein/carbohydrate fermentation balance and microbial population dynamics of the Simulator of Human Intestinal Microbial Ecosystem. Microb Biotechnol 2, 101-113.

22. Topping DL \& Clifton PM (2001) Short-chain fatty acids and human colonic function: roles of resistant starch and nonstarch polysaccharides. Physiol Rev 81, 1031-1064.

23. Hamer HM, Jonkers D, Venema K, et al. (2008) Review Article: the role of butyrate on colonic function. Aliment Pharmacol Ther 27, 104-119.

24. Frankel WL, Zhang W, Singh A, et al. (1994) Mediation of the throphic effects of short-chain fatty acids on the rat jejunum and colon. Gastroenterology 106, 375-380.

25. Roediger WE (1982) Utilization of nutrients by isolated epithelial cells of the rat colon. Gastroenterology 83, 424-429.

26. Wong JM, de Souza R, Kendall CW, et al. (2006) Colonic health fermentation and short-chain fatty acids. J Clin Gastroenterol 40, 235-243.

27. Young GP, Hu Y, Le Leu RK, et al. (2005) Dietary fibre and colorectal cancer: a model for environment-gene interactions. Mol Nutr Food Res 49, 571-584.

28. Borowicki A, Stein K, Scharlau K, et al. (2010) Fermented wheat aleurone inhibits growth and induces apoptosis in human HT29 colon adenocarcinoma cells. Br J Nutr 103, 360-369.

29. Robertson DM (2007) Metabolic cross talk between the colon and the periphery: implications for insulin sensitivity. Proc Nutr Soc 66, 351-361. 
30. Tazoe H, Otomo Y, Kaji I, et al. (2008) Roles of short-chain fatty acids receptors, GPR41 and GPR43 on colonic functions. J Physiol Pharmacol 59, Suppl. 2, 251-262.

31. Hu GX, Chen GR, Xu H, et al. (2010) Activation of the AMP activated protein kinase by short-chain fatty acids is the main mechanism underlying the beneficial effect of a high fiber diet on the metabolic syndrome. Med Hypotheses $\mathbf{7 4}$, $123-126$.

32. Winder WW \& Hardie DG (1999) AMP-activated protein kinase, a metabolic master switch: possible roles in type 2 diabetes. Am J Physiol 277, E1-E10.

33. Zhang BB, Zhou G \& Li C (2009) AMPK: an emerging drug target for diabetes and the metabolic syndrome. Cell Metabol 9, 407-416.

34. Grabitske HA \& Slavin JL (2009) Gastrointestinal effects of low-digestible carbohydrates. Crit Rev Food Sci Nutr 49, $327-360$.

35. Livesey G (2001) Tolerance of low-digestible carbohydrates: a general view. Br J Nutr 85, Suppl. 1, S7-S16.

36. Cloetens L, De Preter V, Swennen K, et al. (2008) Doseresponse effect of arabinoxylooligosaccharides on gastrointestinal motility and on colonic bacterial metabolism in healthy volunteers. J Am Coll Nutr 27, 512-518.

37. Knuiman JT, Hautvast JGAG, Van Der Heyden L, et al. (1986) A multi-centre study on completeness of urine collection in 11 European centres. Some problems with the use of creatinine and 4-aminobenzoic acid as markers of the completeness of collection. Hum Nutr Clin Nutr 50, 229-237.

38. Murakami K, Sasaki S, Takahashi Y, et al. (2008) Sensitivity and specificity of published strategies using urinary creatinine to identify incomplete $24-\mathrm{h}$ urine collection. Nutr $\mathbf{2 4}$, $16-20$.

39. Franks AH, Harmsen HJM, Raangs GC, et al. (1998) Variations of bacterial populations in human feces quantified by fluorescent in situ hybridization with group specific $16 \mathrm{~S}$ rRNA-targeted oligonucleotide probes. Appl Environ Microbiol 64, 3336-3345.

40. Langendijk PS, Schut F, Jansen GJ, et al. (1995) Quantitative fluorescence in situ hybridization of Bifidobacterium spp. with genus-specific 16S rRNA-targeted probes and its application in fecal samples. Appl Environ Microbiol 61, 3069-3075.

41. Harmsen HJM, Elfferich P, Schut F, et al. (1999) A 16S rRNAtargeted probe for detection of lactobacilli and enterococci in faecal samples by fluorescent in situ hybridization. Microb Ecol Health Dis 11, 3-12.

42. Suau A, Bonnet R, Stutren M, et al. (1999) Direct analysis of genes encoding 16S rRNA from complex communities reveals many novel molecular species within the human gut. Appl Environ Microbiol 65, 4799-4807.

43. Aminov R, Walker AW, Duncan SH, et al. (2006) Molecular diversity, cultivation, and improved detection by fluorescent in situ hybridization of a dominant group of human gut bacteria related to Roseburia spp. or Eubacterium rectale. Appl Env Microbiol 72, 6371-6376.

44. Harmsen HJM, Raangs GC, He T, et al. (2002) Extensive set of $16 \mathrm{~S}$ rRNA-based probes for detection of bacteria in human feces. Appl Environ Microbiol 68, 2982-2990.

45. Van de Wiele T, Boon N, Possemiers S, et al. (2004) Prebiotic effects of chicory inulin in the simulator of the human intestinal microbial ecosystem. FEMS Microbiol Ecol 51, 143-153.

46. Yap WKW, Mohamed S, Jamal MH, et al. (2008) Changes in infants faecal characteristics and microbiota by inulin supplementation. J Clin Biochem Nutr 43, 159-166.
47. Bremner JM \& Keeney RD (1965) Steam distillation methods for determination of ammonium, nitrate and nitrite. Anal Chem Acta 32, 485-495.

48. De Loor H, Bammens B, Evenepoel P, et al. (2005) Gas chromatographic-mass spectrometric analysis for measurement of $p$-cresol and its conjugated metabolites in uremic and normal serum. Clin Chem 51, 1535-1538.

49. van Munster IP, de Boer HM, Jansen MC, et al. (1994) Effect of resistant starch on breath-hydrogen and methane excretion in healthy volunteers. Am J Clin Nutr 59, 626-630.

50. Riegler G \& Esposito I (2001) Bristol scale stool form. A still valid help in medical practice and clinical research. Tech Coloproctol 5, 163-164.

51. Maki KC, Carson ML, Miller MP, et al. (2009) Hydroxypropylmethylcellulose lowers cholesterol in statin-treated men and women with primary hypercholesterolemia. Eur J Clin Nutr. 63, 1001-1007.

52. Shapiro SS \& Wilk MB (1965) An analysis of variance test for normality (complete samples). Biometrika 52, 591-611.

53. Conover WJ \& Iman RL (1981) Rank transformations as a bridge between parametric and nonparametric statistics. Am Stat 35, 124-129.

54. Pinheiro JC \& Bates DM. (2004) Mixed-Effects Models in S and S-PLUS. New York: Springer-Verlag.

55. Hothorn T, Bretz F \& Westfall P (2008) Simultaneous inference in general parametric models. Biometrical $J \mathbf{5 0}$, $346-363$.

56. Sidak Z (1967) Rectangular confidence region for the means of multivariate normal distributions. J Am Stat Ass 62, 626-633

57. Hopkins MJ, Sharp R \& Macfarlane GT (2002) Variation in human intestinal microbiota with age. Dig Liv Dis $\mathbf{3 4}$, Suppl. 2, S12-S18.

58. Woodmansey EJ (2007) Intestinal bacteria and ageing. $J$ Appl Microbiol 102, 1178-1186.

59. Roberfroid M (2005) Inulin-Type Fructans. Functional Food Ingredients. Boca Raton, FL: CRC Press.

60. Roberfroid M (2007) Prebiotics: the concept revisited. J Nutr 137, Suppl. 2, 830S-837S

61. Meyer D \& Stasse-Wolthuis M (2009) The bifidogenic effect of inulin and oligofrucotse and its consequences for gut health. Eur J Clin Nutr 63, 1277-1289.

62. Van Dokkum W, Wezendonk B, Srikumar TS, et al. (1999) Effect of nondigestible oligosaccharides on large-bowel functions, blood lipid concentrations and glucose absorption in young healthy male subjects. Eur J Clin Nutr 53, 1-7.

63. Grasten S, Liukkonen K-H, Chrevatidis A, et al. (2003) Effects of wheat pentosan and inulin on the metabolic activity of fecal microbiota and on bowel function in healthy humans. Nutr Res 23, 1503-1514.

64. Causey JL, Feirtag JM, Gallaher DD, et al. (2000) Effects of dietary inulin on serum lipids, blood glucose and the gastrointestinal environment in hypercholesterolemic men. Nutr Res 20, 191-201.

65. Slavin J \& Feirtag J (2011) Chicory inulin does not increase stool weight or speed up intestinal transit time in healthy male subjects. Food Funct 2, 72-76.

66. Kleessen B, Sykura B, Zunft HJ, et al. (1997) Effects of inulin and lactose on fecal microflora, microbial activity, and bowel habit in elderly constipated persons. Am J Clin Nutr 65 1397-1402.

67. Gibson GR, Beatty ER, Wang X, et al. (1995) Selective stimulation of bifidobacteria in the human colon by oligofructose and inulin. Gastroenterology 108, 975-982.

68. Van Laere K, Hartemink R, Bosveld M, et al. (2000) Fermentation of plant cell wall derived polysaccharides and their 
corresponding oligosaccharides by intestinal bacteria. J Agric Food Chem 48, 1644-1652.

69. Falony G, Vlachou A, Verbrugghe K, et al. (2006) Crossfeeding between Bifidobacterium longum BB536 and acetate-converting butyrate-producing colon bacteria during growth on oligofructose. Appl Environ Mirobiol 72, 7835-7841.

70. Morrison DJ, Mackay WD, Edwards CA, et al. (2006) Butyrate production from oligofructose fermentation by the human faecal flora: what is the contribution of extracellular acetate and lactate? Br J Nutr 96, 570-577.

71. Louis P \& Flint HJ (2009) Diversity, metabolism and microbial ecology of butyrate-producing bacteria from the human large intestine. FEMS Microbiol Lett 294, 1-8.

72. Louis P, Young P, Holtrop G, et al. (2010) Diversity of human colonic butyrate-producing bacteria revealed by analysis of the butyryl-CoA:acetate CoA-transferase gene. Environ Microbiol 12, 304-314.

73. Topping DL, Fukushima M \& Bird AR (2003) Resistant starch as a prebiotic and synbiotic. Proc Nutr Soc 62, 171-176.

74. Zampa A, Silvi S, Fabiani R, et al. (2004) Effects of different digestible carbohydrates on bile acid metabolism and SCFA production by human gut micro-flora grown in an in vitro semi-continuous culture. Anaerobe 10, 19-26.

75. Macfarlane GT, Allison C \& Gibson GR (1988) Effect of pH on protease activities in the large intestine. Lett Appl Microbiol 7, 161-164.
76. Bouhnik Y, Vahedi K, Achour L, et al. (1999) Short-chain fructooligosaccharide administration dose-dependently increases faecal bifidobacteria in healthy humans. J Nutr 129, 113-116.

77. Kruse HP, Kleessen B \& Blaut M (1999) Effects of inulin on faecal bifidobacteria in human subjects. Br J Nutr $\mathbf{8 2}$, 375-382.

78. Bouhnik Y, Raskine L, Champion K, et al. (2007) Prolonoged administration of low-dose inulin stimulates the growth of bifidobacteria in humans. Nutr Res 27, 187-193.

79. Bonnema AL, Kolberg LW, Thomas W, et al. (2010) Gastrointestinal tolerance of chicory inulin products. J Am Diet Assoc 110, $865-868$.

80. Tateyama I, Hashii K, Johno I, et al. (2005) Effect of xylooligosaccharide intake on severe constipation in pregnant women. J Nutr Sci Vitaminol 51, 445-448.

81. Den Hond E, Geypens B \& Ghoos Y (2000) Effects of high performance chicory inulin on constipation. Nutr Res $\mathbf{2 0}$, $731-736$.

82. Marteau P, Jacobs H, Cazaubiel M, et al. (2011) Effects of chicory inulin in constipated elderly people: a doubleblind controlled trial. Int J Food Sci Nutr 62, 164-171.

83. François IEJA, Lescroart O, Veraverbeke WS, et al. (2010) Safety assessment of a wheat bran extract containing arabinoxylan-oligosaccharides: mutagenicity, clastogenicity and 90-day rat-feeding studies. Int J Toxicol 29, 479-495. 